\title{
Content Analysis of a Facebook Group as a Form of Mentoring for EFL Teachers
}

\author{
Emrah Cinkara $^{1} \&$ Fadime Yalçın Arslan ${ }^{1}$ \\ ${ }^{1}$ Faculty of Education, Gaziantep University, Gaziantep, Turkey \\ Correspondence: Emrah Cinkara, Faculty of Education, Foreign Langauge Teaching Department, Gaziantep \\ University, 27310, Gaziantep / Turkey. Tel: 90-342-317-2750. E-mail: emrahcinkara@gmail.com
}

Received: November 7, 2016

doi: 10.5539/elt.v10n3p40
Accepted: February 1, 2017 Online Published: February 3, 2017

URL: http://doi.org/10.5539/elt.v10n3p40

\begin{abstract}
Mentoring, a main constituent of teacher education, has taken new shape in recent years, with educators incorporating technology and social media into their practices. This study investigated the use of a Facebook group as a form of informal mentoring among teachers with reference to qualitative and quantitative data collected from the entries, responses and comments of group members. Findings included a list of mentoring topics along with the number of comments and words for each entry. In this way, we were able to analyse quantitatively the contents of each mentoring topic and provide as qualitative evidence clear examples from member comments and exchanges. The findings revealed that EFL teachers shared experiences and knowledge on various topics such as pedagogical knowledge, pedagogical content knowledge, content knowledge, resources and career development.
\end{abstract}

Keywords: informal online mentoring, online teacher communities, teacher learning

\section{Introduction}

Recent studies pertaining to teacher education indicate that online learning and other forms of technology-based learning are becoming a preferred method of course delivery and teacher support (Smith \& Israel, 2010). Teacher support in this sense has been provided in several forms and via diverse media channels, including online web 2 tools. Online tools have emerged as complementary and sometimes even alternative to traditional face-to-face teacher support programs.

Since contexts vary, individuals may develop different types of learning, teaching and mentoring relationships. E-mentoring (or electronic mentoring) is one approach utilized to assist pre-service and in-service teachers. It has emerged as an alternative to face-to-face mentoring, and it has been defined in various ways. For instance, Smith and Israel (2010) define e-mentoring as "the use of computer-mediated communications such as e-mail, discussion boards, chat rooms, blogs, Web conferencing, and growing Internet-based solutions that are changing the way mentors and mentees interact" (p.30). Like face-to-face mentoring, online mentoring also aims to contribute to educators' professional growth primarily via the use of computer-mediated communication tools. Moreover, in response to the time and place constraints cited by some scholars as limiting the effectiveness of face-to-face mentoring, e-mentoring offers flexibility as it is time and place independent (Watson, 2006). Similarly, Bierema and Merriam (2002) identify that through e-mentoring, individuals may have a chance "to cross the boundaries of space, time, geography and culture" (p. 220). It is generally agreed that the interactions of face-to-face mentoring and e-mentoring are similar in nature, with the differences in communication mainly relating to the time and manner in which information has been provided. Since e-mentoring is time and place independent, it might be helpful for busy teachers and for those located in relatively rural or isolated areas who lack access to a large pool of colleagues teaching the same subject.

Professional development for teachers is a lifelong process that involves mentorship at various stages. One dimension of this development is the transferal of theoretical knowledge into practice. Teachers often need support - especially that of colleagues - in applying pedagogical content knowledge to actual teaching practice. During face-to-face mentoring among educators, scaffolding approaches often are taught which aim to foster independent problem-solving. Similarly, online mentoring makes use of scaffolding as a mode of mentorship. In recent years, a large number of publicly accessible online mentoring websites have been created for providing collegial advice and services across a range of professional groups in the education sector. EFL\&ESL Industry is 
one of these websites offering online discussions, support and advice to English language teachers.

\section{Review of Literature}

Mentoring has been the focus of various studies in the field of teacher education (Lindgren, 2005; Kajs, 2002; He, 2010; Hobson \& Maldarez, 2013). The word mentoring derives from Greek mythology, and in Homer's Odyssey, the mentor is described as a reliable, reasonable guide who contributes to the development of Odysseus (Miller, 2002). In recent years, mentoring adopted various definitions. For example, Lindgren (2005) regards mentoring as an active process during which human dynamics are learned and promoted. He (2009) views mentoring as a main constituent of teacher education and focuses on its collaborative nature. Hobson and Maldarez (2013) define mentoring as a one-to-one relationship between a relatively inexperienced teacher (mentee) and a relatively experienced teacher (mentor) who aims to support the mentee's development. Similarly, Akin and Hilbun (2007) define mentoring as a method of transferring knowledge and skills from an experienced professional to a new or junior member of the field.

Studies on mentoring in the context of teacher education have focused on different aspects. Some studies have been conducted in pre-service education (Leshem, 2012; He, 2010), while some have been conducted in in-service education (Russell and Russell, 2011; Kissau and King, 2014, Lindgren, 2005). Furthermore, mentor-mentee relationships have been investigated in some of these studies (M. I. Russell \& J. A. Russell, 2011; Leshem, 2012; Allen, Day \& Lentz, 2005).

The benefits of the mentoring process for mentees has been one of the primary focuses of mentoring studies. Mentees can utilize the experiences and knowledges of their mentors in order to develop themselves professionally (Arslan, Cinkara, Bağçeci, \& Kervancioğlu, 2016). Discussion between both parties may encourage mentees to reflect upon their thoughts, thus developing an increased self-awareness regarding their professional development. Similarly, there is a growing body of research indicating that mentor-mentee relationships enhance the professional development of mentors, as well (Iancu-Haddad \& Oplatka, 2009). Lindgren (2005) supports this idea by claiming that mentors can benefit from the mentoring process, with mentees' reflections, thoughts and beliefs providing unrealized and new possibilities. Kram and Isabella (1985) support this idea, as well, asserting that during the mentoring process, mentors find internal satisfaction and gain respect from colleagues.

In terms of the behaviors and functions of mentoring, mutual confidence is considered essential for effective relationships (Risquez, 2008). Guest (2000) emphasizes that sharing experience, offering encouragement and developing insights are important features of mentoring. Ensher, Heun, and Blanchard (2003) explain that mentors fulfill three different functions for their mentees. Firstly, mentors offer "vocational or instrumental support" which influences mentees' careers. Secondly, mentors offer "psychosocial support" including friendship and encouragement. Thirdly, mentors act as role models by displaying appropriate behaviors. According to Jacobi (1991), mentors act as role models, provide personal support and enhance the professional development of mentees. On the other hand, Kram (1986) asserts that mentors can provide two functions - assisting in mentees' career development and serving as personal role models. Feiman-Nemser and Parker (1992) assert an additional three categories of mentorship: mentors as "local guides" who help novice teachers find solutions to their immediate problems and assimilate into schools; mentors as "educational companions" who aid mentees in terms of their classroom practices; and mentors as "agents of change" who aim to encourage "shared inquiry" and "collaboration" (p.492). Mentor function may be influenced by factors such as how the mentoring relationship is formed as well as its duration. Related to these factors, two forms of mentoring exist: formal and informal mentoring.

\subsection{Formal and Informal Mentoring}

Studies on mentoring generally support two models: formal mentoring, which is generally structured by a third party; and informal mentoring, which has little or no intervention by a third party. Raggins (2002) claims that mutual identification and interpersonal comfort lead to the development of informal mentoring. However, in formal mentoring, individuals are matched as part of a development process, in which individuals need to expend the effort to familiarize themselves with each other. Additionally, in terms of timing and structure, formal mentoring is governed by a third party who dictates what should be achieved and how long it should last. Formal mentoring programs are designed for certain periods of time. However, in informal mentoring relationships, the individuals decide whether to proceed (Raggins \& Cotton, 1999). This may lead to different outcomes for each form of mentoring. Informal mentoring relationships may have more time for improving the mentee's professional growth and this may encourage the development of long-term goals.

In informal mentoring, the mentor and mentee may have known each other previously, and this may lead to 
interpersonal comfort. However, in formal mentoring, the mentor and mentee may not have met prior to being matched. Therefore, identification, role modeling and interpersonal comfort may not play an effective role in the development of formal mentoring.

The motivation of mentors and mentees is another potential difference between formal and informal mentoring. Raggins and Cotton (1999) assert that mentors may not be ready to be mentors and they may have been included in such a process because of an authority. Because of this, formal mentors may not be as motivated as informal mentors to enhance the professional growth of mentees. Moreover, if they are not ready for such a process, they may lack effective communication skills required for interacting with mentees (Kram, 1986). Formal mentors may be thought as effective by the organization or the authority, but if mentees do not share the same view, their relationships may not be as effective as expected. By contrast, informal mentoring relationships, which are voluntary, lack similar outside pressure. Because of the relaxed atmosphere created by informal mentoring, the mentor may even provide more psychosocial and professional support than required.

According to the above definitions, e-mentoring can be considered as informal, and it has been defined in various ways. For example, Mihram (2004) describes e-mentoring as a relationship between a more-experienced and a less-skilled person, independent of geography. The fundamental means of communication between the two parties in e-mentoring is electronic (Hamilton \& Scandura, 2003). Bierema and Merriam (2002) define e-mentoring as a computer-mediated process that includes counseling, modeling, support and mutually shared knowledge. Some researchers think that traditional mentoring and e-mentoring have the same outcomes (Knouse, 2001, Risquez, 2008), while others believe that they differ in certain regards. As mentioned previously, in terms of timing and geography, e-mentoring is thought to differ from traditional face-to-face mentoring. Mentors and mentees may overcome barriers such as time limitation and place constraints in e-mentoring relationships. Moreover, e-mentoring is considered more convenient for communication than in-person meetings because individuals may not find a common available time to meet. Hence, e-mentoring provides flexibility in scheduling. It is also believed that online mentoring may provide a neutral, third-party perspective because both parties are aware of the fact that they may not meet face-to face (Harrington, 1999). Despite these advantages, some researchers believe that e-mentoring may also have drawbacks because electronic medium communiqués are found unclear and unsuitable for helpful transfers. When all is considered, the establishment of trusting mutual relationships is essential for both forms of mentoring (Premkumar and Wong, 2010). Effective relationships may arouse ongoing reflections leading to the development of beneficial outcomes for both parties.

Existing research on both types of mentoring reveals that both mentors and mentees receive valuable benefits (Ensher, Thomas, \& Murphy, 2001). The interaction between both parties can be explained by Vygotsky's (1987) scaffolding theory. Scaffolding denotes the helpful interactions between a learner and a more knowledgeable person who enables the learner to achieve something independent of the mentor. One of the important constructs in scaffolding theory is the zone of proximal development (ZPD). ZPD is the field between what a learner can achieve by him/herself and what he/she can accomplish with the help of a more knowledgeable person. In mentoring, the interaction between mentor and mentee can be thought as ZPD. A mentee may improve his/her professional growth through the support, counseling, modeling and encouragement provided by a mentor. In fact, in a study by Miller (1999), participants in an online mentoring program for teachers expressed that they had gained suggestions for lesson plans and found solutions to problems related to their teaching. Miller (1999) also supports the claim that the pre-service teachers and mentees require pedagogical and content knowledge during the mentoring process. Related to this, Schulman (1987) classifies the teacher's knowledge-base into seven categories: content knowledge, which is a subject matter knowledge; pedagogical knowledge, which includes strategies for classroom management and organization; pedagogical content knowledge, which indicates how particular topics are organized, sequenced, presented and adapted for a particular group of learners; knowledge of learners and their characteristics; knowledge of curriculum; and knowledge of educational contexts and ends. Schulman (1987) argues that having content knowledge and pedagogical knowledge is insufficient for gaining the knowledge of good teachers. He believes that they cannot be separated in the classroom, so teachers need pedagogical content knowledge to teach, as well. It is thought that in any stage of their teaching, teachers may need support for their knowledge base. This can be supplemented by a mentor, who is more experienced.

For our study, a mentor is defined as a person who is giving advice and supporting another individual who is asking for help and knowledge. A mentee is the person who is asking for support. In our study, mentors might act as mentees in some situations and they might as mentors in other situations. Members asking for help in some situations are in the position of supporting and helping other members in the group.

\subsection{Research Rationale and Questions}


Research on informal and e-mentoring has been conducted almost exclusively in the education and administration fields, with mentoring-related literature in language-teacher education remaining rather limited. Furthermore, to the best of our knowledge, there is no single research about the nature and functionality of informal e-mentoring for English-language teachers. Therefore, this study investigates the use of social media as a form of informal e-mentoring for English-language teachers. The following research questions guide this study:

1) Concerning which topics did EFL teachers write entries on the Facebook group?

2) Which topics attracted the most interaction, determined by the number of comments and words-per-entry?

3) Which topics attracted the least interaction, determined by number of comments and words-per-entry?

\section{Methods}

\subsection{Research Design}

This study employed a qualitative research paradigm and followed an ethnographic design involving a holistic picture of a group of people engaged in e-mentoring via social media. This design provided researchers with the opportunity to "document or portray the everyday experiences of individuals by observing and interviewing them and relevant others" (Fraenkel, Wallen, \& Hyun, 2011, p. 507).

\subsection{Sampling}

The researchers investigated group members' entries and related comments rather than the posts of individual members. Since it was not possible to analyse the whole body of entries in the group, the researchers randomly selected an eight-week duration. The entries included in the study were submitted for a six-week duration prior to the commencement of the 2015 Fall Semester, i.e. between August $10^{\text {th }}$ and November $10^{\text {th }}$. Therefore, a convenience sampling strategy was utilized.

\subsection{Participants}

This study investigated the use of the Facebook group "EFL \& ESL Industry Network (EEIN)" as a form of informal e-mentoring. EEIN is an open group designated for English language teachers' information exchange regarding various topics. It is an expanding group with a member count of 13,107 as of 18 December 2015. In this sense, all group members were included in the study, but only the data from members who created an entry or made a comment between the given study period were included in the study.

\subsection{Data Collection and Analysis}

The data collection procedure commenced after written permission was granted from the manager of the EEIN group. A purposive selection was used by the researchers based on their observations and experiences among a variety of similar Facebook groups. The high number and activity rate of its members played a critical role in selection of the EEIN, which had 13,876 members. As explained in the sampling procedure, the entries created during the given time period were recorded by the researchers on a word processor. The final document was 320 pages with a 129,947 -word count.

The document was divided into halves and shared between researchers for qualitative analysis. The researchers examined individual entries and recorded the topic of entry along with its purpose. Then, the topics and purposes were investigated and categorized under general headings; thus, a final list was generated by the researchers including all causes and general categories, where applicable. For reliability and validity purposes, these categories and data were presented to a colleague with a doctorate degree in English Language Teaching. The colleague provided feedback on analysis of comments and categorization of purposes. After the expert opinion, the final version of the category list was created and this version guided the researchers' second data analysis.

In the second analysis, the researchers tagged each entry based on its purpose as well as the number of comments for the entry and total number of words. As a result, the data from the second analysis constructed the basis for this study. Then, the records were analyzed qualitatively and quantitatively. The qualitative analysis included the investigation of each entry based on its content and purpose.

\section{Findings and Results}

This study aimed to investigate the use of social media as a form of informal e-mentoring for English-language teachers and employed quantitative and qualitative data analysis. Therefore, the findings of the EEIN investigation are presented respectively. 


\subsection{Quantitative Findings of the EEIN Entries}

The EEIN group is a familiar platform which enables its members to share almost anything within the limits of social media and provides them with the opportunity to improve themselves in many ways. The analysis of entries during the given two-month time period yielded quantitative results regarding the number of entries, comments and words. The results are given in the table below:

Table 1 . Summary of initial quantitative findings

\begin{tabular}{lll}
\hline Total number of entries & Total number of comments & Total number of words \\
\hline 360 & 3338 & 129947 \\
\hline
\end{tabular}

As indicated in the table, a total of 360 entries were created in the given time period and 3,234 comments were made on these entries. The total number of words, 129,897, indicates how broad the size of the data actually is. The data collected and analyzed was immense and is given in-detail in Appendix A.

Further analysis revealed quantitative results regarding the categories for entry content. The number of entries, comments and words for each category are given in Figures 1, 2, and 3:

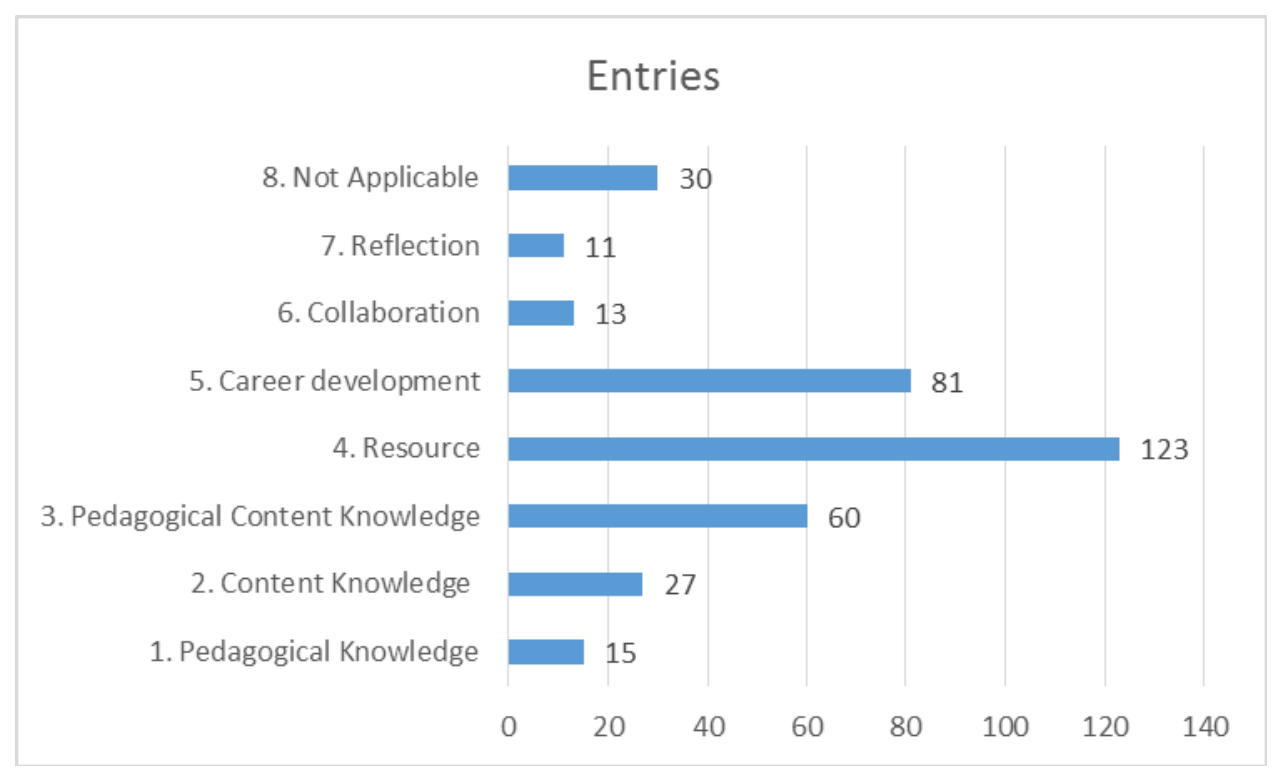

Figure 1. Number of entries per category

Figure 1 presents the number of entries in each category. In the given two-month period, the most actively used category in EEIN was Resources $(\mathrm{N}=123)$. It attracted about fifty percent more entries than the second most common category, Career development $(\mathrm{N}=81)$. The least active category in terms of writing entries was Reflection with only 11 entries in eight-week period. Further analysis revealed number of comments in each category and the results are given in Figure 2: 


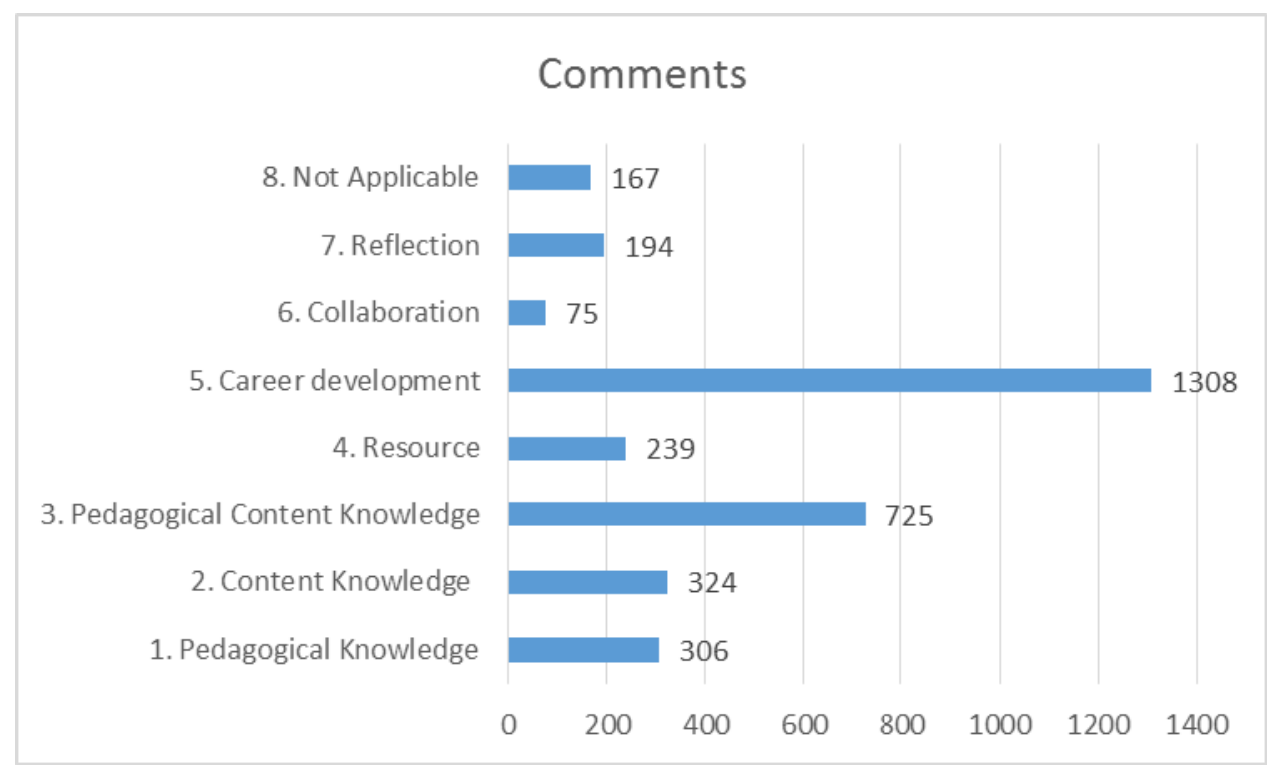

Figure 2. Number of comments per category

Although members most frequently wrote entries regarding resources, these entries did not attract as many comments as expected. Instead, the most active category in terms of member comments was Career Development $(\mathrm{N}=1308)$. The second most active category was Pedagogical Content Knowledge $(\mathrm{N}=725)$, in which members wrote on issues such as teaching specific English forms and functions effectively. Figure 3 presents the number of words per category:

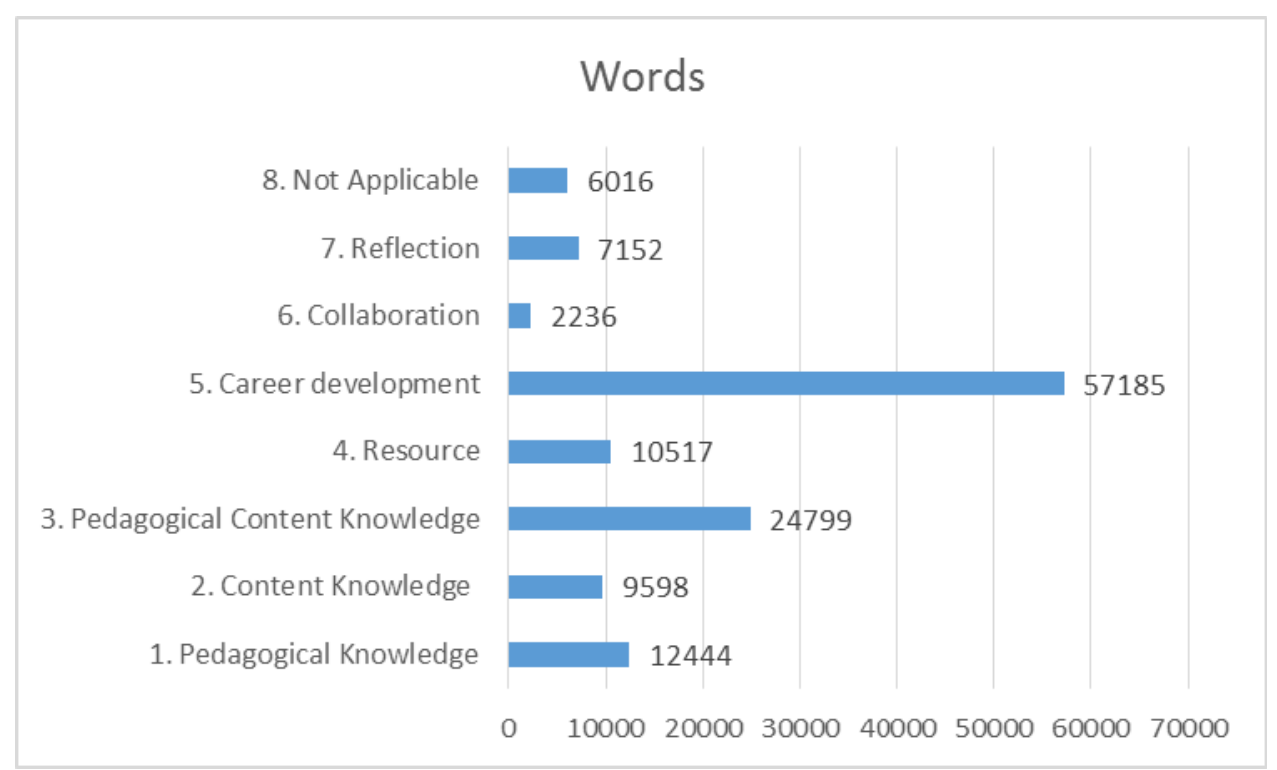

Figure 3. Number of words per category

Similar to the comments, the most active category in terms of the total number of words in comments was Career Development $(\mathrm{N}=57185)$. The closest number of words was observed in Pedagogical Content Knowledge with 24,799 words.

In summary, the analysis of the entries in the EEIN group during given time periods revealed eight main categories: pedagogical knowledge, content knowledge, pedagogical content knowledge, resources, career development, collaboration, reflection and unrelated. The table given in Appendix A displays the distribution of quantitative findings regarding the content analysis of data. A simpler view of the data is given in the figures 
above, which show that members most commonly write entries regarding resources; however, they are more actively interacting and exchanging information in Career Development.

\subsection{Qualitative Findings of the EEIN Entries}

\subsubsection{Pedagogical Knowledge}

This kind of knowledge comprehensively includes the pedagogical tools and techniques that would enable teachers to deliver their subject matter effectively to learners. Therefore, this category included entries in which EFL teachers requested information on the ways of organizing and delivering subject matter. Of the 360 total entries, almost $5 \%$ were in this category $(\mathrm{N}=15)$. Although they sought expertise and information exchange on various topics, we could categorize them into two major sub-categories, namely classroom management and other issues. In classroom management, the participants investigated the techniques necessary for teaching English effectively in their respective contexts. As the participant in Entry 5 below suggested, their aim was to attract all students' attention to the activities they were doing in class.

Good morning everyone! HELP/ADVICE PLEASE! I work in Spain and I have a class of 7/8 year olds (6 boys and 3 girls) 4 of them are my students from last year and we are about to start on the path towards Cambridge starters. However, 2 of the boys are quite disruptive (I.e. they act bored even though they don't know the things we are reviewing or when another student is taking their turn) and another girl looks completely annoyed for the whole class and thinks she knows everything! My problem here isn't discipline as I can manage bad behaviour but term has just started and I want to start as I mean to go on. Could anyone recommend some ways to stimulate them all or specific games or activities? The obvious objective here is exam - based so I need to get all of the elements into the classes. I'm sure it's just early days but any help would be greatly appreciated! (Entry 5).

Other entries in this category included shadings and comments regarding how to build healthy, affective relationships with students (Entry 53), how to deal with boredom, and how to motivate class participation.

After many years of teaching English as a Foreign language to people of all ages, I finally learned the secret of teaching...being friends with your students. It is the most important ingredient (Entry 53).

\subsubsection{Content Knowledge}

In order to teach any subject matter, teachers must possess a comprehensive amount of that subject-matter knowledge. This knowledge is different from pedagogical content knowledge because pedagogical content knowledge not only requires the knowledge of the subject matter itself, but also the knowledge of effective teaching methods and techniques (Richards, 1991). Therefore, in this study, we differentiated between content knowledge (knowledge of subject matter) and pedagogical content knowledge (knowledge of subject matter and teaching).

This kind of knowledge is of prime importance especially for non-native EFL teachers, as they may always experience language components unfamiliar to them. Therefore, in this category, the EEIN group members requested knowledge on the appropriate use of English rather than how to teach language. There were 27 entries with 324 comments requesting help or sharing information in two main areas, namely vocabulary and grammar of English. For example, one member was unsure about the meaning of two words and created an entry about it (Entry 11). This entry gathered 17 comments explaining the difference between these two lexical items.

Good morning fellow teachers, can you please help me with the following: what's the difference between 'normal' and 'common'? Thanks for the help! (Entry 11)

The EEIN group members also made exchanges regarding language use. One might think that in this modern age, it might be more convenient to search the answer online rather than ask in a group and wait for others to reply. However, we have noticed that the entries and comments were not on simple issues - they regarded rather intricate topics, e.g. the following:

Quick question for AMERICAN speakers of English. 'Everyday' vs 'every day'.

To me as a Brit 'everyday' means normal/nothing special/routine. An everyday occurrence - i.e. nothing unusual. 'Every day' means frequency - I walk my dog every day.

My question - are the two interchangeable in American English? My Korean co-teacher says they are - but if so, it's news to me (Entry 89).

As you can see, this entry is not simply asking about a word or a simple language structure that even a native speaker might contemplate for a few seconds, let alone a non-native teacher. 


\subsubsection{Pedagogical Content Knowledge}

As is explained in the previous category, pedagogical content knowledge consists not only of language knowledge but also of how to teach it effectively (Richards, 1991). This kind of knowledge is generally described as being central to teacher's work and not possessed by subject matter experts who are not teaching (Marks, 1990).

There were 60 entries in the following eight sub-categories: reading, writing, speaking, listening, assessment, use of English, pronunciation, young learners and general. Members of the EEIN mostly shared ideas about how to teach speaking $(\mathrm{N}=17,28.3 \%)$ and grammar $(\mathrm{N}=14,23.3 \%)$, which comprised half of the entries in this category. To illustrate with an example, Entry 11 suggested that other members incorporate phonics in EFL classes from the beginning which, in his view, increases interest and speed of learning. He also shared an article link to support his opinion, as seen below:

Below is link to an article that discusses the importance of a phonetic approach to teaching reading in English to children and adults.

It says:

“......beginning readers who focus on letter-sound relationships, or phonics, increase activity in the area of their brains best wired for reading.

...in other words, to develop reading skills, teaching students to sound out "C-A-T" sparks more optimal brain circuitry than instructing them to memorize the word "cat"....."

I have always used phonics in my EFL classes. I do not use the IPA but a system based on how Spanish speakers, more or less, would write certain sounds.

I focus on the most difficult sounds at first. (Entry 11)

\subsubsection{Resources}

This category reflects the entries in which members shared suggestions about various resources including textbooks $(\mathrm{N}=5,4,1 \%)$, resource books $(\mathrm{N}=11,8,9 \%)$, online materials $(\mathrm{N}=40,32,5 \%)$, tests $(\mathrm{N}=4,3,2 \%)$, visuals and charts $(\mathrm{N}=48,39,2 \%)$, plays to act out $(\mathrm{N}=6,4,9 \%)$, and games $(\mathrm{N}=9,7,3 \%)$. As could be expected, the weighing of this category in terms of number and percentage in all entries was relatively higher than that of other categories $(\mathrm{N}=123,34,1 \%)$.

\subsubsection{Career Development}

One of the major purposes of the EEIN was to serve as a platform for its members to exchange information on a variety of professional issues experienced by both native and non-native EFL teachers. We investigated entries and comments regarding career development. There were 81 entries and 1,308 comments in this category. Our content analysis yielded three sub-categories about entries in career development-overall professional-teaching $(\mathrm{N}=15,18,5 \%)$, specific $(\mathrm{N}=51,62,9 \%)$, and degree and certificate programs $(\mathrm{N}=15,18,52 \%)$.

In overall professional development, users wrote entries or asked for advice on general teaching education practices to improve their careers. For example, in Entry 217 below, the teachers wanted some advice on their first day at a specific institution:

Hi Everyone! Im in need for some tips and advices from some of you, more experienced fellow teachers.

I will be starting my first volunteering role as an ESOL teacher this Saturday. I have never met my group before, all $\mathrm{i}$ know about them is that they are beginner English speakers; mostly boys aged 15-18. The class is not course book based, as new people can/will attend to every class and there is no written record of what topics/vocabulary/grammar they had covered with their previous teacher.

Any advice is much appreciated,

Many thanks x (Entry 217)

In the specific sub-category, members mostly asked or shared information about teaching positions, required qualifications, working conditions, cultural and social status of teaching in the country, wages, and many others. This sub-category constructed more than half of the entries in this category, which illustrates the nature of the EEIN as a tool for improving career opportunities for EFL professionals. For example, the comment below provides detailed information on how the EFL profession is regarded in given countries and finishes with invaluable advice:

the world of TEFL has changed alot, I have been living in Poland for 11 years, I only did my celta last year and 
do not have a degree but finding a full time job is so hard, no sick or holiday pay and generally treated like muck, so moving to spain, still not sure how it'll be, but usually they pay sick andd holiday pay from what $\mathrm{i}$ can gather. I have a friend who works in China and he has great money, but a lot of dodgy schools everywhere. for YL i think you need nerves of steel nad maybe the YLE is good, i may need to move to teaching kids and less and less adults need English. most schools only care about profit and my advice, do not work for a school which is owned by a non teacher (Comment in Entry 187).

Finally, in the third sub-category, information on degree and certificate programs were exchanged and entries mostly asked for expert opinions of experience with these programs. For example, in Entry 189, a group member asked about the CELTA course in Turkey. Then, another member replied with the following:

In general the price is about 1,200 GBP plus accommodation and travel costs. It takes one month full time to complete. It would be better to do it locally in your own country if you can, or find a country that has a weak currency rate and a low cost of living could help help (A comment to Entry 189).

\subsubsection{Collaboration}

This category contains entries and comments in which teachers seek ways to cooperate with each other. This cooperation included but was not limited to requests for actively working together, building situations in which their students would work together, and deriving feedback on their work. In one instance, a member asked about pen-pal opportunities for her students and it received 22 comments, stating willingness to match students with pen-pals:

Hi all,

I am interested in finding penpals for my students in japan (preferably by postal letter, not e-mail). It would be nice if I could hook them up with students around their age ( 8 to 13) from any country. Their English level isn't that great so finding native speakers isn't essential. I would like one penpal for each student and there are 28 students.

Please send me a message if you're interested.

Best wishes. (Entry 93)

Another cooperation area in the EEIN was attracting active participants or users in the projects, blogs, and web pages they had created. In one case, a member created a web page on which teachers could create feelings charts with their own pictures or, if permitted, with their students' pictures:

Create your own personal chart of *FEELINGS and EMOTIONS* by having your learners take pictures of each other. Use the chart below as a guide. Elicit the vocabulary from learners first, and then break them into groups. Break-out all those smart phones, cameras, laptops, and add a touch of social media (Pinterest, Facebook, Picmonkey). Makes for fun learning and allows learners to integrate technology into their learning process. Stand back and watch what happens. Step in only when you hear grammar and vocabulary corrections need to be made. Also, adds that personal touch! This little project promises to be a great adventure in learning - for teachers and learners. (Entry 103)

\subsubsection{Reflection}

Entries in this category were mainly asking for and giving feedback on work and professional experiences. Although there were few entries in this category $(\mathrm{N}=11,3,06 \%)$, subsequent comments and answers provided valuable feedback and reflection about EFL teachers' professional lives. To give an example, in Entry 23 below, a member asked for colleagues' opinion about a choice she had to make:

Hello everyone! I'm Maria and am a ESL teacher in Bolivia. I want to go teach abroad and was thinking on going to China or South Korea. I would like some feedback on which you guys think would be better to start with. Also, is Bridge TEFL online certification good? Which one is the one you guys have? Thanks! (Entry 23)

In one of the entries, a member created a blog spot for his students and shared this blog with the EEIN group to derive feedback:

After a few students had asked me what some of the cartoons meant, I decided to write up a post about it. Feedback is welcome. (Entry 69)

\subsubsection{Not Applicable}

The last group contains entries involving topics unrelated to EFL teachers' professional development. There were 30 entries with 167 comments in this category, most of which were advertisements and touristic experiences. Therefore, they were not of value for this study. 
A final investigation was conducted to provide an analytical view on the number of comments per entry, i.e. comment-to-entry ratio (CER), and the number of words per entry, i.e. word-to-entry ratio (WER). Through this analysis, the number of comments and words were counted and divided by the number of entries in each category; thus, their ratios were calculated. In this way, we show how comprehensive each category was and also provide a means to compare the extent to which each category gathered attention from EEIN members. The table below shows the number of comments and words per entry:

Table 3. Number of comments and words per entry in each category

\begin{tabular}{lll}
\hline & comment to entry ratio (CER) & word to entry ratio (WER) \\
\hline 1. Pedagogical Knowledge & 20,4 & 829,6 \\
2. Content Knowledge & 12,0 & 355,5 \\
3. Pedagogical Content Knowledge & 12,1 & 413,3 \\
4. Resource & 1,9 & 85,5 \\
5. Career development & 16,1 & 706,0 \\
6. Collaboration & 5,8 & 172,0 \\
7. Reflection & 17,6 & 650,2 \\
8. Not Applicable & 5,6 & 200,5 \\
\hline Overall total & 9,3 & 361,0 \\
\hline
\end{tabular}

As is clearly seen in Table 3, the highest CER was observed in Pedagogical Knowledge with 20,4 comments per entry; Reflection and Career Development followed it with 17,6 and 16,1 comments per entry, respectively. In a similar vein, pedagogical knowledge, career development and reflection were the three categories attracting the highest number of words per entry, 829,6, 706,0 and 650,2 WER figures respectively. On the other hand, the lowest CER $(\mathrm{N}=1,9)$ and WER $(\mathrm{N}=85,5)$ values were observed in Resources.

\section{Discussion}

The total number of entries, comments and words in the EEIN group during given time periods indicated that social media was used efficiently by participants as a form of informal mentoring. When quantitative analysis regarding the content of entries was considered, Resources was observed to have the highest percentage. While the percentage of entries for Resources was quite high, the percentage of the total number of comments and words for the same category was quite low. On the other hand, the highest percentage for the total number of comments and words belonged to Career Development in all categories. Pedagogical Content Knowledge followed it in all categories. These findings indicate that, although the number of resources shared was high, there was no interaction among the participants. The participants did not seek feedback or information exchange for the resources they shared. However, in Career Development, EFL teachers shared information on various topics. Since the EEIN group included participants from around the world, EFL teachers may have felt that they could easily obtain first-hand knowledge and support in terms of career development. Another reason might be the relationship between being a member of such a social media group and the feeling of developing oneself professionally. The need for professional development might lead people to be a member of such group, resulting in career development.

The highest CER observed in Pedagogical Knowledge was another significant finding for the present study. While the highest percentage for the total number of comments and words belonged to Career Development, the highest number of words per entry was observed in Pedagogical Knowledge and was followed by Reflection. It could be inferred that the participants preferred to be members of this social media group because they needed the knowledge of how to improve themselves and, thus, used content knowledge more efficiently. This idea could be supported by Schulman (1987), who claimed that possessing content knowledge and pedagogical knowledge alone is not enough in order to be a good teacher. He claimed that teachers needed pedagogical content knowledge, as well, in order to teach effectively. Thus, the high number of PK might indicate that teachers need more knowledge about how to teach.

When existing categories are considered, it can be inferred that mentoring relationships are viewed as a way of enhancing professional development (Bierema \& Merriam, 2002; Kajs, 2002; Iancu-Haddad \& Oplatka, 2009). 
Moreover, sharing experience and developing insights are observed to be important for the participants involved (Guest, 2000). When the whole process is considered, it is observed that both the person sharing an entry and the people commenting on it made use of the process. This finding can be supported by research findings in the literature reviewed in this study (Lindgren, 2005; Kram \& Isabella, 1985).

Another significant finding relates to the high number of entries in comparison to the short amount of time and participants who had joined that group. The degree of informal mentoring might have enabled participants to be more flexible and comfortable because they were aware of the fact that they might not meet face-to-face and could interact easily. As Harrington (1999) claimed, they might have thought that such a form of online informal mentoring would supply a more impartial perspective and relaxed atmosphere.

\section{Conclusion}

This study explored the nature and functionality of informal e-mentoring for English language teachers, but it did not distinguish pre-service from in-service teachers. Further research might proceed with such distinction. Furthermore, demographic features of the participants were not considered. It might also be held as a variable in further studies. For the present study, the content of a six-month period was investigated. Further studies might engage the content of a longer period.

\section{References}

Akin, I., \& Hilbun, J. (2007). E-mentoring in three voices. Online Journal of Distance Learning Administration, 10(1). Retrieved from http://www.westga.edu/ distance/ojdla/spring101/akin101.htm

Allen, T. D., Day, R., \& Lentz, E. (2005). The role of interpersonal comfort in mentoring relationships. Journal of Career Development , 31(3), 155-169. http://dx.doi.org/10.1177/089484530503100301

Arslan, F. Y., Cinkara, E., Bağçeci, B., \& Kervancioğlu, Ş. (2016). Mentoring as a Professional Development Activity for EFL Teachers: A Case of a Tertiary Level English Preparatory Program. Mustafa Kemal University Journal of Graduate School of Social Sciences, 13(34), 150-165.

Bierema, L., \& Merriam, S. (2002). E-mentoring: Using computer mediated communication to enhance the mentoring process. Innovative Higher Education, 26(3), 211-227. http://doi.org/10.1023\%2FA\%3A1017921023103

Darwin, A. (2000). Critical reflections on mentoring in work settings. Adult Education Quarterly, 50(3), 197-211. http://dx.doi.org/10.1177/07417130022087008

Ensher, E. A., Heun, C., \& Blanchard, A. (2003). Online mentoring and computer-mediated communication: New directions in research. Journal of educational behaviour, 63(2), 264-288. http://dx.doi.org/10.1016/S0001-8791(03)00044-7

Ensher, E. A., Thomas, C., \& Murphy, S. E. (2001). Comparison of traditional, step-ahead, and peer mentoring on proteges' support, satisfaction, and perceptions of career success: A social exchange perspective. Journal of Business and Psychology, 15(3), 419-438. https://doi.org/10.1023/A:1007870600459

Feiman-Nemser, S., \& Parker, M. B. (1992). Mentoring in context: A comparison of two U.S. programs for beginning teachers (NCRTL special report). Michigan State University: East Lansing, MI: National Center for Research on Teacher Learning.

Fraenkel, J. R., Wallen, E. N., \& Hyun, H. H. (2011). How to Design and Evaluate Research in Education. New York: McGraw-Hill Humanties/Social Sciences/Languages.

Guest, G. (2000). Coaching and mentoring in learning organizations. 5th Intarnational ASHRM Conference. Manama, Bahrain.

Hamilton, B. A., \& Scandura, T. A. (2003). E-mentoring: Implications for organizational learning and development in a wired world. Organizational Dynamics, 31(4), 388-402. https://doi.org/10.1016/S0090-2616(02)00128-6

Harrington, A. (1999). E-mentoring: the advantages and disadvantages of using email to support distance mentoring. $\quad$ European Social Fund. Retrieved at http://www.coachingnetwork.org.uk/information-portal/Articles/ViewArticle.asp?artId=63

He, Y. (2010). Strength-based mentoring in pre-service teacher educa tion: A literature review. Mentoring and Tutoring: Partnership in learning, 17(3), 263-275. http://dx.doi.org/10.1080/13611260903050205 
Hobson, A. J., \& Maldarez, A. (2013). Judgementoring and other threats to realizing the potential of school-based mentoring in teacher education. International Journal of mentoring and coaching in education, 2(2), 89-108. http://dx.doi.org/10.1108/IJMCE-03-2013-0019

Iancu-Haddad, D., \& Oplatka, L. (2009). Mentoring novice teachers: Motives, process and outcomes from the mentor's point of view. The New Educator, 5(1), 45-65. http://dx.doi.org/10.1080/1547688X.2009.10399563

Jacobi, M. (1991). Mentoring and undergraduate academic success: A review of the literature. Review of Educational Research, 61(4), 505-532. https://doi.org/10.3102/00346543061004505

Kajs, L. T. (2002). Framework for designing a mentoring program for novice teachers. Mentoring and Tutoring, 10(1), 57-69. http://dx.doi.org/10.1080/13611260220133153

Kissau, S. P., \& King, E. T. (2015). Peer mentoring second language teachers: A mutually beneficial experience?. Foreign Language Annals, (48), 143-160. http://dx.doi.org/10.1111/flan.12121

Knouse, S. B. (2001). Virtual mentors: Mentoring on the Internet. Journal of Employment Counseling, 38(4), 162-169. http://dx.doi.org/10.1002/j.2161-1920.2001.tb00498.x

Kram, K. E., \& Isabella, L. A. (1985). Mentoring alternatives: the role of peer relationships in career development. Academy of Management Journal, 28(1), 110-132. http://dx.doi.org/10.2307\%2F256064

Kram, K. (1986). Mentoring in the workplace. In D. Hall (Ed.), Career Development in Organizations (pp. 160-201). San Francisco: Jossey-Bass.

Leshem, S. (2012). The many faces of mentor-mentee relationships in a pre-service teacher education programme. Creative Education, 3(4), 413-421. http://dx.doi.org/10.4236/ce.2012.34065

Lindgren, U. (2005). Experiences of beginning teachers in a school-based mentoring programme in Sweden. Educational studies , 31(3), 251-63. http://dx.doi.org/10.1080/03055690500236290

Mihram, D. (2004). E-mentoring. USC: Center for Excellence in Teaching.

Miller, K. (1999). Mentoring via Mouse. Retrieved at http://www.startribune.com

Miller, A. (2002). Mentoring students \& young people: A handbook of effective practice. London: Kogan Page. https://doi.org/10.4324/9780203417188

Murray, M. (1991). Beyond the Myths and Magic of Mentoring: How to Facilitate an Effective Mentoring Program. San-Francisco: Jossey-Bass.

Raggins, B. R. (2002). Understanding diversified mentoring relationships: Definitions, challenges, and strategies. In D. Clutterbuch, \& B. R. Raggins (Eds), Mentoring and Diversity: An International Perspective (pp. 23-53). Woburn, MA: Butterworth Heinmann. https://doi.org/10.1016/B978-0-7506-4836-3.50004-5

Raggins, B. R., \& Cotton, J. L. (1999). Mentor functions and outcomes: A comparison of men and women in formal and informal mentoring relationships. Journal of Applied Psyhology, 84(4), 529-550. https://doi.org/10.1037/0021-9010.84.4.529

Risquez, A. (2008). E-mentoring: An extended practice, an emerging discipline. In F. Garcia-Penalvo (Ed.), Adcances in E-learning: Experiences and Methodologies (pp. 61-82). Hershey, PA: Information Science Publishing. https://doi.org/10.4018/978-1-59904-756-0.ch004

Russell, M. I., \& Russell, J. A. (2011). Mentoring relationships: Cooperating teachers' perspectives on mentoring student interns. The Professional Educator, 35(1), 16-35.

Schulman, L. (1987). Knowledge and teaching: Foundations of the new reform. Harward Educational Review, 57(1), 1-22. https://doi.org/10.17763/haer.57.1.j463w79r56455411

Smith, S. J., \& Israel, M. (2010). E-mentoring: Enhancing special education teacher induction. Journal of Special Education Leadership. 23(1), 30-40.

Thomsen, S., \& Gustafson, R. (1997). Turning practitioners into professors: Exploring effective mentoring

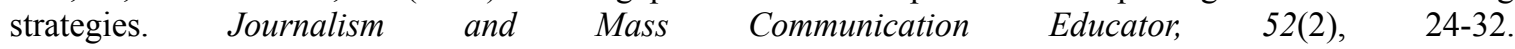
http://dx.doi.org/10.1177/107769589705200203

Vygotsky, L. (1987). Collected works of Vygotsky. Volume 1.Problems of general psychology including the volum thinking and speech. New York and London: Plenum Press.

Watson, S. (2006). Virtual mentoring in higher education: Teacher education and cyber-connections. International Journal of Teaching and Learning in Higher Education, 18(3), 168-179. 
Premkumar, K., \& Wong, A. (2010). Mentoring principles, processes, and strategies for facilitating mentoring

relationships at a distance.
http://doi.org/10.15766/mep_2374-8265.3148

Mededportal

Publications,

2000(6),

34-46.

\section{Appendix}

\section{Quantitative Figures Regarding the Content of Entries}

\begin{tabular}{|c|c|c|c|c|c|c|c|c|c|}
\hline \multirow{3}{*}{ 1. Pedagogical Knowledge } & \multicolumn{4}{|c|}{ Entries } & \multicolumn{3}{|c|}{ Comments } & \multicolumn{2}{|c|}{ Words } \\
\hline & \multirow[t]{2}{*}{$\#$} & \multicolumn{3}{|c|}{$\%$ in category $\%$ in total \# } & \multicolumn{3}{|c|}{$\%$ in category $\%$ in total $\#$} & \multicolumn{2}{|c|}{$\%$ in category $\%$ in tota } \\
\hline & & & & & & & & & \\
\hline 1.1 Classroom management & 4 & 26,67 & 1,11 & 110 & 35,95 & 3,30 & 5654 & 45,44 & 4,35 \\
\hline 1.2 Other issues & 11 & 73,33 & 3,06 & 196 & 64,05 & 5,87 & 6790 & 54,56 & 5,23 \\
\hline Category total & 15 & & 4,17 & 306 & & 9,17 & 12444 & & 9,58 \\
\hline \multicolumn{10}{|l|}{ 2. Content Knowledge } \\
\hline 2.1 Vocabulary & 15 & 55,56 & 4,17 & 214 & 66,05 & 6,41 & 6072 & 63,26 & 4,67 \\
\hline 2.2 Grammar (use of English) & 12 & 44,44 & 3,33 & 110 & 33,95 & 3,30 & 3526 & 36,74 & 2,71 \\
\hline Category total & 27 & & 7,50 & 324 & & 9,71 & 9598 & & 7,39 \\
\hline \multicolumn{10}{|l|}{ 3. Pedagogical Content Knowledge } \\
\hline 3.1 Reading & 3 & 5,00 & 0,83 & 32 & 4,41 & 0,96 & 1640 & 6,61 & 1,26 \\
\hline 3.2 Writing & 8 & 13,33 & 2,22 & 66 & 9,10 & 1,98 & 2795 & 11,27 & 2,15 \\
\hline 3.3 Speaking & 17 & 28,33 & 4,72 & 176 & 24,28 & 5,27 & 6390 & 25,77 & 4,92 \\
\hline 3.4 Assessment & 4 & 6,67 & 1,11 & 35 & 4,83 & 1,05 & 2215 & 8,93 & 1,70 \\
\hline 3.5 Use Of English & 14 & 23,33 & 3,89 & 104 & 14,34 & 3,12 & 50 & 0,20 & 0,04 \\
\hline 3.6 Pronunciation & 4 & 6,67 & 1,11 & 58 & 8,00 & 1,74 & 1765 & 7,12 & 1,36 \\
\hline 3.7 Young Learners & 6 & 10,00 & 1,67 & 102 & 14,07 & 3,06 & 4598 & 18,54 & 3,54 \\
\hline 3.8 General-Type Not Specified & 4 & 6,67 & 1,11 & 152 & 20,97 & 4,55 & 5346 & 21,56 & 4,11 \\
\hline Category total & 60 & & 16,67 & 725 & & 21,72 & 24799 & & 19,08 \\
\hline \multicolumn{10}{|l|}{ 4. Resource } \\
\hline 4.1 Textbook & 5 & 4,07 & 1,39 & 30 & 12,55 & 0,90 & 821 & 7,81 & 0,63 \\
\hline 4.2 Resource book & 11 & 8,94 & 3,06 & 55 & 23,01 & 1,65 & 2222 & 21,13 & 1,71 \\
\hline 4.3 Online material & 40 & 32,52 & 11,11 & 17 & 7,11 & 0,51 & 2236 & 21,26 & 1,72 \\
\hline 4.4 Tests & 4 & 3,25 & 1,11 & 7 & 2,93 & 0,21 & 203 & 1,93 & 0,16 \\
\hline 4.5 Visuals and charts & 48 & 39,02 & 13,33 & 86 & 35,98 & 2,58 & 2870 & 27,29 & 2,21 \\
\hline 4.6 Play to act & 6 & 4,88 & 1,67 & 5 & 2,09 & 0,15 & 378 & 3,59 & 0,29 \\
\hline 4.7 Games & 9 & 7,32 & 2,50 & 39 & 16,32 & 1,17 & 1787 & 16,99 & 1,38 \\
\hline Category total & 123 & & 34,17 & 239 & & 7,16 & 10517 & & 8,09 \\
\hline \multicolumn{10}{|l|}{ 5. Career development } \\
\hline 5.1 Overall professional-teaching & 15 & 18,52 & 4,17 & 190 & 14,53 & 5,69 & 9433 & 16,50 & 7,26 \\
\hline 5.2 Specific (about the culture, people, salary, opportunities, etc.) & 51 & 62,96 & 14,17 & 790 & 60,40 & 23,67 & 34014 & 59,48 & 26,18 \\
\hline 5.3 Degree and Certificate Programs (MA, TEFL, CELTA, DELTA, Conference, Online) & 15 & 18,52 & 4,17 & 328 & 25,08 & 9,83 & 13738 & 24,02 & 10,57 \\
\hline Category total & 81 & & 22,50 & 1308 & & 39,19 & 57185 & & 44,01 \\
\hline 6. Collaboration & 13 & & 3,61 & 75 & & 2,25 & 2236 & & 1,72 \\
\hline 7. Reflection & 11 & & 3,06 & 194 & & 5,81 & 7152 & & 5,50 \\
\hline
\end{tabular}




\section{Copyrights}

Copyright for this article is retained by the author(s), with first publication rights granted to the journal.

This is an open-access article distributed under the terms and conditions of the Creative Commons Attribution license (http://creativecommons.org/licenses/by/4.0/). 